\title{
Metagenomic screening of microbiomes identifies pathogen-enriched environments
}

\author{
Xiaofang Li*
}

\begin{abstract}
Background: Human pathogens are widespread in the environment, and examination of pathogen-enriched environments in a rapid and high-throughput fashion is important for development of pathogen-risk precautionary measures. In this study, a Local BLASTP procedure for metagenomic screening of pathogens in the environment was developed using a toxin-centered database. A total of 69 microbiomes derived from ocean water, freshwater, soils, feces, and wastewater were screened using the Local BLASTP procedure. Bioinformatic analysis and Canonical Correspondence Analysis were conducted to examine whether the toxins included in the database were taxonomically associated.

Results: The specificity of the Local BLASTP method was tested with known and unknown toxin sequences. Bioinformatic analysis indicated that most toxins were phylum-specific but not genus-specific. Canonical Correspondence Analysis implied that almost all of the toxins were associated with the phyla of Proteobacteria, Nitrospirae and Firmicutes. Local BLASTP screening of the global microbiomes showed that pore-forming RTX toxin, ornithine carbamoyltransferase ArgK, and RNA interferase Rel were most prevalent globally in terms of relative abundance, while polluted water and feces samples were the most pathogen-enriched.

Conclusions: The Local BLASTP procedure was applied for rapid detection of toxins in environmental samples using a toxin-centered database built in this study. Screening of global microbiomes in this study provided a quantitative estimate of the most prevalent toxins and most pathogen-enriched environments. Feces-contaminated environments are of particular concern for pathogen risks.
\end{abstract}

Keywords: Metagenomics, Microbiome, Local BLASTP, Toxins, Pathogens

\section{Background}

Rapid identification of pathogens in a particular environment is important for pathogen-risk management. Human pathogens are ubiquitous in the environment, and infections from particular environments have been reported worldwide. For example, soil-related infectious diseases are common [1, 2]. Legionella longbeachae infection has been reported in many cases, mainly due to potting mixes and composts [3]. Survival of enteric viruses and bacteria has also been detected in various water environments, including aquifers and lakes [4-7].

\footnotetext{
*Correspondence: xfli@sjziam.ac.cn
}

Key Laboratory of Agricultural Water Resources, Hebei Key Laboratory of Soil Ecology, Centre for Agricultural Resources Research, Institute of Genetics and Developmental Biology, Chinese Academy of Sciences, No. 286, Huaizhong Rd, Shijiazhuang 050021, China
Examination of pathogens from infected individuals with a particular clinical syndrome has been a major achievement of modern medical microbiology [8]. Nevertheless, we still know little about the magnitude of the abundance and diversity of known common pathogens in various environments, which is very important for the development of appropriate precautions for individuals who come in contact with certain environmental substrates. This can be realized through metagenomic detection of pathogenic factors in a time-efficient and high-throughput manner using next-generation sequencing methods [8].

Metagenomic detection of pathogens can be accomplished through different schemes. Li et al. [9] examined the level and diversity of bacterial pathogens in sewage treatment plants using a 16S rRNA amplicon-based 
metagenomic procedure. Quantitative PCR has also been applied for monitoring specific pathogens in wastewater [10]. More studies have applied the whole-genomeassembly scheme to detect one or multiple dominant pathogens, most of which were for viral detection in clinical samples [11-14]. Although metagenomic-based whole-genome-assembly for bacterial pathogen detection can be conducted at the single species level [15], its computational requirements are high if it is in a highthroughput fashion. In 2014, Baldwin et al. [16] designed the PathoChip for screening pathogens in human tissues by targeting unique sequences of viral and prokaryotic genomes with multiple probes in a microarray. This approach can screen virtually all pathogen-enriched samples in a high-throughput manner.

Despite the aforementioned progress in metagenomic tools for pathogen detection, metagenomic screening for bacterial pathogens in environments such as soil, where microbial diversity is tremendous, is still challenging. This is mostly due to difficulty in assembling short reads generated by next-generation sequencing [8]. The whole-genome-assembly approach is efficient at identifying viromes, but not at dealing with bacterial pathogens from metagenomes especially when target pathogens are of low abundance. Amplicon-based approaches are able to detect bacterial pathogens in a high-throughput manner; however, it is well known that phenotypic diversity exists widely across and within microbial species of a genus because of divergent evolution $[17,18]$. This also holds true for pathogenic factors [19]. Moreover, toxin factors, such as the Shiga toxin (stx) of Shigella, are primarily transferable through lateral gene transfer, which leads to the continuous evolution of pathogen species [20]. Therefore, it is necessary to examine the pathogen diversity in environmental metagenomes using essential virulence genes as biomarkers.

In this study, a toxin-centered virulence factors database was built, and the well-developed Local BLASTP method was applied to detect virulence factors in various environments. This procedure is metagenome-based and can be conducted in a high-throughput fashion, which greatly simplifies development of precautions for pathogen-enriched environments.

\section{Methods and materials}

\section{Environments and their metagenomes}

Sixty-nine metagenomes were selected and downloaded from the MG-RAST server (Table 1). These metagenomes were derived from ocean water, freshwater, wastewater, natural soil, deserts, and feces, representing the major environmental media found worldwide. Sequencing methods of the metagenomes include the illumina, Ion Torrent and 454 platforms, and predicted proteins in the metagenomes ranged from 33,743 (fresh water, ID mgm4720261) to $11,587,259$ (grassland soil, ID mgm 4623645). The gene-calling results from the MG-RAST server were used for toxin factor screening in this study. The taxonomic composition at the genus level was also retrieved from the MG-RAST server for 27 representative metagenomes.

\section{Toxin factor database}

A toxin-centered database was established for bacterial pathogen detection in metagenomes in this study. Candidate toxin factors for pathogenic screening of environmental metagenomes were gathered based on well-studied pathogens summarized in the Virulence Factor Database [21], a soil borne pathogen report by Jeffery and van der Putten [2], and a manure pathogen report by the United States Water Environment Federation [22]. Sequences of the toxin factors were then retrieved by searching the UniProt database using the toxin plus pathogen names as an entry [23], while typical homologs at a cut-off $E$ value of $10^{-6}$ were gathered from GenBank based on BLAST results. A protein database was then built for Local BLSATP study (Additional file 1). Considering that virulence process involves several essential factors including toxins, various pathogen-derived secretion proteins were also included in the database, and it was tested that whether secretion proteins were as specific as toxin proteins for pathogen detection. The disease relevance of all virulence factors was screened using the WikiGenes system [24] and relevant publications (Table 2).

\section{Local BLASTP}

The Local BLASTP was applied following the procedure used in our previous study $[58,59]$. Basically, the gene-calling results of each metagenome were searched against the toxin factor database using BLASTP. The cutoff expectation $E$ value was set as $10^{-6}$. The results of the Local BLASTP were then copied to an Excel worksheet, after which they were subjected to duplicate removal, quality control, and subtotaled according to database ID. Duplicate removal was based on the hypothesis that each sequence contains one copy of a specific toxin factor, since the gene-calling results were used. For quality control of the BLAST results, a cut-off value of $40 \%$ for identity and 20 aa $[1 / 3$ of the length of the shortest toxin factors (e.g., the Heat-Stable Enterotoxin C)] for query alignment length were used to filter the records. The toxins abundance matrix was formed for subsequent analyses. 
Table 1 General information regarding the metagenomes retrieved from the MG-RAST server

\begin{tabular}{|c|c|c|c|c|c|c|c|c|c|}
\hline MG-RAST ID & Abbreviation & bp count & $\begin{array}{l}\text { Sequence } \\
\text { count }\end{array}$ & $\begin{array}{l}\text { Protein } \\
\text { predicted }\end{array}$ & Material & Location & Country & Coordinates & $\begin{array}{l}\text { Sequencing } \\
\text { method }\end{array}$ \\
\hline mgm4440281 & MW281 & $35,439,683$ & 334,386 & 227,038 & $\begin{array}{l}\text { Mine drain- } \\
\text { age }\end{array}$ & $\begin{array}{l}\text { Soudan } \\
\text { Mine }\end{array}$ & USA & $\begin{array}{l}47.819 \\
\quad-92.243\end{array}$ & 454 \\
\hline mgm4443754 & WW754 & $24,210,189$ & 54,344 & 58,182 & Waste water & Singapore & Singapore & $1.332,103.754$ & Unknown \\
\hline mgm4443755 & WW755 & $30,035,399$ & 57,827 & 62,600 & Waste water & Singapore & Singapore & $1.332,103.755$ & Unknown \\
\hline mgm4443756 & WW756 & $29,292,896$ & 61,672 & 65,312 & Waste water & Singapore & Singapore & $1.332,103.756$ & Unknown \\
\hline mgm4461675 & FW675 & $156,809,137$ & 389,864 & 258,015 & Well water & $\begin{array}{l}\text { Lashkardi } \\
\text { village }\end{array}$ & Bangladesh & $23.744,90.606$ & 454 \\
\hline mgm4507016 & F016 & $163,648,718$ & 227,551 & 250,347 & Feces & Bologna & Italy & $44.495,11.343$ & Illumina \\
\hline mgm4510939 & FW939 & $76,571,419$ & 97,768 & 106,497 & $\begin{array}{l}\text { Surface } \\
\text { water }\end{array}$ & Minnesota & USA & $\begin{array}{l}43.000 \\
\quad-91.000\end{array}$ & Illumina \\
\hline mgm4510941 & FW941 & $49,162,469$ & 56,117 & 68,954 & $\begin{array}{l}\text { Surface } \\
\text { water }\end{array}$ & Minnesota & USA & $\begin{array}{l}47.000 \\
\quad-95.000\end{array}$ & Illumina \\
\hline mgm4510942 & FW942 & $26,796,913$ & 42,585 & 49,581 & $\begin{array}{l}\text { Surface } \\
\text { water }\end{array}$ & Minnesota & USA & $\begin{array}{l}45.000 \\
\quad-94.000\end{array}$ & Illumina \\
\hline mgm4510943 & FW943 & $52,372,093$ & 74,178 & 86,925 & $\begin{array}{r}\text { Surface } \\
\text { water }\end{array}$ & Minnesota & USA & $\begin{array}{l}45.000 \\
\quad-94.000\end{array}$ & Illumina \\
\hline mgm4510944 & FW944 & $53,884,243$ & 72,536 & 84,028 & $\begin{array}{l}\text { Surface } \\
\text { water }\end{array}$ & Minnesota & USA & $\begin{array}{l}44.000 \\
\quad-93.000\end{array}$ & Illumina \\
\hline mgm4510945 & FW945 & $54,142,157$ & 71,478 & 83,751 & $\begin{array}{l}\text { Surface } \\
\text { water }\end{array}$ & Minnesota & USA & $\begin{array}{l}44.000 \\
-93.000\end{array}$ & Illumina \\
\hline mgm4510946 & FW946 & $49,216,363$ & 74,745 & 83,253 & $\begin{array}{l}\text { Surface } \\
\text { water }\end{array}$ & Minnesota & USA & $\begin{array}{l}43.000 \\
\quad-93.000\end{array}$ & Illumina \\
\hline mgm4514299 & DS299 & $322,114,449$ & 242,0832 & $1,323,378$ & $\begin{array}{l}\text { Saline } \\
\text { Desert } \\
\text { Soil }\end{array}$ & $\begin{array}{l}\text { Gujarat of } \\
\text { India }\end{array}$ & India & $\begin{array}{r}23.7925 \\
71.008\end{array}$ & Ion torrent \\
\hline mgm4533707 & OW707 & $134,833,790$ & 668,257 & 508,217 & $\begin{array}{c}\text { Brackish } \\
\text { Water }\end{array}$ & $\begin{array}{l}\text { Columbia } \\
\text { River } \\
\text { coastal } \\
\text { margin, } \\
\text { OR \&WA }\end{array}$ & USA & $\begin{array}{l}46.265 \\
\quad-123.999\end{array}$ & Illumina \\
\hline mgm4543019 & DS019 & $282,578,916$ & $2,016,127$ & 842,475 & $\begin{array}{l}\text { Saline } \\
\text { Desert } \\
\text { Soil }\end{array}$ & $\begin{array}{l}\text { Gujarat of } \\
\text { India }\end{array}$ & India & $23.908,70.538$ & Ion torrent \\
\hline mgm4546371 & WW371 & $84,424,005$ & 907,785 & 803,682 & Wastewater & $\begin{array}{l}\text { Universiti } \\
\text { Teknologi } \\
\text { Malaysia }\end{array}$ & Malaysia & $2.558,104.642$ & Illumina \\
\hline mgm4556493 & AS493 & $162,926,938$ & $1,613,138$ & $1,332,131$ & $\begin{array}{l}\text { Activated } \\
\text { sludge }\end{array}$ & Unkown & China & $\begin{array}{l}31.550 \\
120.315\end{array}$ & Illumina \\
\hline mgm4556497 & AS497 & $162,926,938$ & $1,613,138$ & $1,278,907$ & $\begin{array}{l}\text { Activated } \\
\text { sludge }\end{array}$ & Unkown & China & $\begin{array}{l}31.551 \\
\quad 120.316\end{array}$ & Illumina \\
\hline mgm4556505 & AS505 & $257,249,323$ & $2,547,023$ & $1,737,663$ & $\begin{array}{l}\text { Activated } \\
\text { sludge }\end{array}$ & Unkown & China & $\begin{array}{l}31.552 \\
120.316\end{array}$ & Illumina \\
\hline mgm4556509 & AS509 & $41,926,615$ & 415,115 & 330,475 & $\begin{array}{l}\text { Activated } \\
\text { sludge }\end{array}$ & Unkown & China & $\begin{array}{l}31.552 \\
120.317\end{array}$ & Illumina \\
\hline mgm4560423 & F423 & $22,734,940$ & 73,479 & 76,569 & Feces & $\begin{array}{l}\text { Lake Eyasi, } \\
\text { Tanzania }\end{array}$ & Tanzania & $\begin{array}{r}-3.635 \\
35.083\end{array}$ & Illumina \\
\hline mgm4568577 & MW577 & $10,065,266$ & 50,137 & 34,287 & Mine water & Guangdong & China & $\begin{array}{l}\text { 24.503 } \\
\quad 113.710\end{array}$ & 454 \\
\hline mgm4568580 & MW580 & $12,911,442$ & 62,018 & 36,461 & Mine water & Guangdong & China & $\begin{array}{l}22.940 \\
112.050\end{array}$ & 454 \\
\hline mgm4589537 & FW537 & $337,068,782$ & $2,099,471$ & $1,842,975$ & $\begin{array}{l}\text { Surface } \\
\text { water }\end{array}$ & $\begin{array}{l}\text { West } \\
\text { Virginia }\end{array}$ & USA & $\begin{array}{l}38.094 \\
\quad-81.959\end{array}$ & Illumina \\
\hline mgm4620487 & WW487 & $147,523,219$ & 696,132 & 640,283 & Wastewater & $\begin{array}{c}\text { Guelph ON } \\
\text { Canada }\end{array}$ & Canada & $\begin{array}{l}43.544 \\
\quad-80.248\end{array}$ & Illumina \\
\hline mgm4620488 & WW488 & $115,131,556$ & 578,337 & 537,267 & Wastewater & $\begin{array}{c}\text { Guelph ON } \\
\text { Canada }\end{array}$ & Canada & $\begin{array}{l}43.545 \\
\quad-80.248\end{array}$ & Illumina \\
\hline
\end{tabular}


Table 1 (continued)

\begin{tabular}{|c|c|c|c|c|c|c|c|c|c|}
\hline MG-RAST ID & Abbreviation & bp count & $\begin{array}{l}\text { Sequence } \\
\text { count }\end{array}$ & $\begin{array}{l}\text { Protein } \\
\text { predicted }\end{array}$ & Material & Location & Country & Coordinates & $\begin{array}{l}\text { Sequencing } \\
\text { method }\end{array}$ \\
\hline mgm4620491 & BS491 & $52,759,415$ & 244,855 & 238,630 & Biosolides & $\begin{array}{l}\text { Guelph ON } \\
\text { Canada }\end{array}$ & Canada & $\begin{array}{l}43.545 \\
\quad-80.248\end{array}$ & Illumina \\
\hline mgm4623645 & S645 & $1,541,232,730$ & $15,259,730$ & $11,587,259$ & $\begin{array}{l}\text { Grassland } \\
\text { soil }\end{array}$ & MPG_Ranch & USA & $\begin{array}{l}46.682 \\
-114.027\end{array}$ & Illumina \\
\hline mgm4626292 & S292 & $711,577,500$ & $7,115,775$ & $5,992,554$ & $\begin{array}{l}\text { Mountain } \\
\text { soil }\end{array}$ & $\begin{array}{l}\text { Taishan, } \\
\text { Guang- } \\
\text { dong, } \\
\text { China }\end{array}$ & China & $\begin{array}{l}22.110 \\
\quad 112.770\end{array}$ & Illumina \\
\hline mgm4629146 & D146 & $1,693,361,056$ & $9,120,345$ & $3,914,215$ & Dust & Valencia & Spain & $\begin{array}{l}39.466 \\
\quad-0.366\end{array}$ & Illumina \\
\hline mgm4654022 & S022 & $830,740,317$ & $4,484,452$ & $4,110,948$ & $\begin{array}{l}\text { Mountain } \\
\text { soil }\end{array}$ & $\begin{array}{l}\text { northern } \\
\text { Galilee } \\
\text { Moun- } \\
\text { tains }\end{array}$ & Israel & $33.000,35.233$ & Illumina \\
\hline mgm4654023 & S023 & $711,633,780$ & $3,762,792$ & $3,377,414$ & Soil & Terra Rossa & Israel & $31.700,35.050$ & Illumina \\
\hline mgm4654025 & S025 & $698,042,789$ & $3,808,872$ & $3,379,500$ & Soil & Terra Rossa & Israel & $31.700,35.050$ & Illumina \\
\hline mgm4654028 & S028 & $572,066,482$ & $3,129,422$ & $2,798,806$ & Soil & Rendzina & Israel & $31.033,34.9$ & Illumina \\
\hline mgm4679248 & S248 & $603,919,746$ & $3,365,512$ & $1,361,948$ & Soil & Seoul & South Korea & $\begin{array}{l}37.460 \\
126.948\end{array}$ & Illumina \\
\hline mgm4679254 & S254 & $689,019,062$ & $3,688,750$ & $1,966,121$ & Soil & Seoul & South Korea & $\begin{array}{l}37.459 \\
126.948\end{array}$ & Illumina \\
\hline mgm4695622 & PFW622 & $114,430,648$ & 111,889 & 148,833 & $\begin{array}{l}\text { Polluted } \\
\text { fresh } \\
\text { water }\end{array}$ & $\begin{array}{l}\text { Nanjing, } \\
\text { Jiangsu }\end{array}$ & China & $\begin{array}{l}32.600 \\
118.160\end{array}$ & Illumina \\
\hline mgm4695626 & PFW626 & $86,732,360$ & 78,621 & 111,489 & $\begin{array}{l}\text { Polluted } \\
\text { fresh } \\
\text { water }\end{array}$ & $\begin{array}{l}\text { Nanjing, } \\
\text { Jiangsu }\end{array}$ & China & $\begin{array}{l}32.400 \\
\quad 118.140\end{array}$ & Illumina \\
\hline mgm4697397 & OS397 & $143,214,978$ & 397,067 & 299,940 & Organic Soil & Beijing & China & $\begin{array}{l}32.054 \\
\quad 118.763\end{array}$ & Illumina \\
\hline mgm4713197 & OW197 & $60,417,678$ & 272,918 & 140,195 & $\begin{array}{l}\text { Ocean } \\
\text { water }\end{array}$ & Moorea & $\begin{array}{l}\text { Pacific } \\
\text { Ocean }\end{array}$ & $\begin{array}{l}17.538 \\
\quad-149.829\end{array}$ & Illumina \\
\hline mgm4713202 & OW202 & $89,726,117$ & 442,552 & 254,139 & $\begin{array}{l}\text { Ocean } \\
\text { water }\end{array}$ & Moorea & $\begin{array}{l}\text { Pacific } \\
\text { Ocean }\end{array}$ & $\begin{array}{l}17.538 \\
-149.829\end{array}$ & Illumina \\
\hline mgm4713205 & OW205 & $106,474,596$ & 476,363 & 235,777 & $\begin{array}{l}\text { Ocean } \\
\text { water }\end{array}$ & Moorea & $\begin{array}{l}\text { Pacific } \\
\text { Ocean }\end{array}$ & $\begin{array}{l}17.538 \\
-149.829\end{array}$ & Illumina \\
\hline mgm4718752 & F752 & $329,518,322$ & $1,312,822$ & 950,489 & Feces & Upstate NY & USA & $\begin{array}{l}42.668 \\
-76.528\end{array}$ & Illumina \\
\hline mgm4719940 & OW940 & $360,335,259$ & $1,425,556$ & $1,023,445$ & $\begin{array}{l}\text { Ocean } \\
\text { water }\end{array}$ & Irish Sea & $\begin{array}{l}\text { Atlantic } \\
\text { Ocean }\end{array}$ & $\begin{array}{l}53.225 \\
\quad-4.159\end{array}$ & Illumina \\
\hline mgm4720261 & FW261 & $35,487,527$ & 6,896 & 33,743 & Fresh Water & Galway & Ireland & $\begin{array}{l}53.276 \\
\quad-9.060\end{array}$ & Illumina \\
\hline mgm4740560 & MT560 & $739,577,348$ & $7,322,548$ & $6,102,709$ & Mine tailing & Kamloops & Canada & Unkown & Illumina \\
\hline mgm4763187 & F187 & $1,605,883,158$ & $10,011,241$ & $3,022,645$ & Feces & $\begin{array}{l}\text { Palmerston } \\
\text { North }\end{array}$ & $\begin{array}{l}\text { New Zea- } \\
\text { land }\end{array}$ & $\begin{array}{r}-40.355 \\
175.612\end{array}$ & Illumina \\
\hline mgm4763293 & F293 & $1,621,471,323$ & $9,844,890$ & $3,391,304$ & Feces & $\begin{array}{l}\text { Palmerston } \\
\text { North }\end{array}$ & $\begin{array}{l}\text { New Zea- } \\
\text { land }\end{array}$ & $\begin{array}{r}-40.355 \\
175.612\end{array}$ & Illumina \\
\hline mgm4763371 & F371 & $1,455,357,314$ & $9,241,610$ & $2,388,304$ & Feces & $\begin{array}{l}\text { Palmerston } \\
\text { North }\end{array}$ & $\begin{array}{l}\text { New Zea- } \\
\text { land }\end{array}$ & $\begin{array}{r}-40.355 \\
175.612\end{array}$ & Illumina \\
\hline mgm4770614 & S614 & $55,225,990$ & 132,807 & 144,038 & Forest soil & Leningrad & Russia & $59.549,31.399$ & Illumina \\
\hline mgm4779571 & DS571 & $226,100,954$ & $1,707,504$ & $1,288,831$ & Desert soil & $\begin{array}{l}\text { Kutch } \\
\text { Desert }\end{array}$ & India & $23.941,70.188$ & Ion Torrent \\
\hline mgm4779573 & OW573 & $126,222,705$ & 403,606 & 341,516 & Saline water & Lake Tyrrel & Australia & $-35.32,142.8$ & 454 \\
\hline mgm4779575 & OW575 & $46,134,631$ & 135,959 & 130,566 & Saline water & Albufera & Spain & $\begin{array}{l}39.332 \\
-0.352\end{array}$ & 454 \\
\hline mgm4779577 & OW577 & $26,544,332$ & 80,951 & 44,824 & Saline water & Lake Tyrrel & Australia & $\begin{array}{r}-35.320 \\
142.800\end{array}$ & 454 \\
\hline
\end{tabular}


Table 1 (continued)

\begin{tabular}{|c|c|c|c|c|c|c|c|c|c|}
\hline MG-RAST ID & Abbreviation & bp count & $\begin{array}{l}\text { Sequence } \\
\text { count }\end{array}$ & $\begin{array}{l}\text { Protein } \\
\text { predicted }\end{array}$ & Material & Location & Country & Coordinates & $\begin{array}{l}\text { Sequencing } \\
\text { method }\end{array}$ \\
\hline mgm4779580 & OW580 & $10,257,469$ & 80,645 & 60,571 & Saline water & $\begin{array}{l}\text { British__ } \\
\text { Columbia }\end{array}$ & Canada & $\begin{array}{l}49.730 \\
\quad-119.874\end{array}$ & Ion Torrent \\
\hline mgm4779582 & OW582 & $236,630,443$ & 691,427 & 455,629 & Saline water & Santa Pola & Spain & $\begin{array}{l}38.200 \\
\quad-0.600\end{array}$ & 454 \\
\hline mgm4779585 & SE585 & $69,798,594$ & 852,769 & 442,408 & Sediment & $\begin{array}{l}\text { Yilgarn_Cra- } \\
\text { ton }\end{array}$ & Australia & $\begin{array}{r}-33.426 \\
121.689\end{array}$ & Illumina \\
\hline mgm4779589 & OW589 & $10,713,143$ & 81,307 & 61,739 & Saline water & $\begin{array}{l}\text { British } \\
\text { Columbia }\end{array}$ & Canada & $\begin{array}{l}49.730 \\
\quad-119.874\end{array}$ & Ion torrent \\
\hline mgm4784118 & SE118 & $294,673,007$ & 263,221 & 400,006 & Sediment & $\begin{array}{l}\text { St. Francis } \\
\text { Bay }\end{array}$ & South Africa & $\begin{array}{c}-34.190 \\
24.704\end{array}$ & Ion Torrent \\
\hline mgm4784267 & SE267 & $337,590,087$ & 280,494 & 451,716 & Sediment & Cape Recife & South Africa & $\begin{array}{c}-34.045 \\
25.569\end{array}$ & Ion Torrent \\
\hline mgm4795328 & FW328 & $1,263,293,418$ & $5,301,996$ & $2,970,195$ & $\begin{array}{l}\text { Surface } \\
\text { water }\end{array}$ & San Antonio & USA & $\begin{array}{l}29.424 \\
\quad-98.493\end{array}$ & Illumina \\
\hline mgm4819059 & S059 & $658,065,701$ & $4,358,051$ & $2,432,031$ & Forest soil & Lahti & Finland & $60.971,25.704$ & Illumina \\
\hline mgm4819062 & S062 & $1,197,697,874$ & $7,931,774$ & $6,478,848$ & Forest soil & Baltimore & USA & $\begin{array}{l}39.488 \\
\quad-76.689\end{array}$ & Illumina \\
\hline mgm4819067 & S067 & $771,429,857$ & $5,108,807$ & $3,703,810$ & $\begin{array}{l}\text { Grassland } \\
\text { soil }\end{array}$ & $\begin{array}{l}\text { Potchef- } \\
\text { stroom }\end{array}$ & South Africa & $\begin{array}{c}-26.701 \\
27.101\end{array}$ & Illumina \\
\hline mgm4819073 & S073 & $730,894,511$ & $4,840,361$ & $3,946,449$ & Forest soil & Baltimore & USA & $\begin{array}{l}39.326 \\
-76.622\end{array}$ & Illumina \\
\hline N/A & SRS & $532,850,584$ & $1,632,914$ & $1,408,943$ & Red Soil & Mt Isa & Australia & $\begin{array}{l}\text { 20.440, } \\
\quad 139.300\end{array}$ & Illumina \\
\hline N/A & SRSP & $433,386,397$ & $1,338,665$ & $1,081,822$ & $\begin{array}{l}\text { Red soil } \\
\text { polluted }\end{array}$ & Mt Isa & Australia & $\begin{array}{l}20.440 \\
\quad 139.300\end{array}$ & Illumina \\
\hline N/A & SSLS & $507,124,889$ & $1,552,234$ & $1,413,889$ & $\begin{array}{l}\text { Shrub land } \\
\text { soil }\end{array}$ & Mt Isa & Australia & $\begin{array}{l}\text { 20.440, } \\
139.300\end{array}$ & Illumina \\
\hline
\end{tabular}

\section{Specificity tests of the Local BLASTP method}

Sequences from the toxin database established in this study, as "known sequences" to the database, were selected randomly and searched against the database using the BLASTP procedure. The genome of Clostridium perfringens ATCC 13124 (NC_008261), as "unknown" sequences to the database, was subject to the Local BLASTX procedure as well. Homologous proteins were searched exhaustively in the GenBank database using BLASTP, with the representative toxin factors in the toxins database as a query. Sequences were retrieved and aligned using ClustalW [60], and Maximum-likelihood phylogeny was conducted with MEGA 7 [61].

\section{Data analysis}

The toxin frequency in each metagenome was normalized to a total gene frequency of 10,000,000 to eliminate the effects of gene pool size. Toxin abundance in the 69 metagenomes was visualized using Circos [62]. The genus abundance of 27 selected metagenomes representing the main environment types was calculated and sorted by genus name, followed by manual construction of a genus abundance matrix for subsequent biodiversity-toxin abundance Canonical Correspondence Analysis using R [63] with the package 'vegan' [64].

\section{Results and discussion}

In this study, a toxin-centered database was built for bacterial pathogen screening in various microbiomes through a Local BLASTP procedure. The specificity of the procedure was tested, the relative abundance of toxins in the microbiomes was examined, and the toxintaxonomic abundance correspondence analysis was performed.

Like the previously established Local BLASTN method for antibiotic and metal resistance genes screening [58, $59,65]$, the Local BLASTP method using the toxincentered pathogen database in this study was successful at accurately identifying toxin proteins from the database. For screening of the Clostridium perfringens ATCC 13124 genome, the methods successfully detected the pore-forming genes and multiple copies of the glucosyltransferase (toxB-like) and ADP-ribosyltransferase (spvB-like) genes, based on the raw data. These results are consistent with the virulence genetic features of Clostridium sp. [21], which have not been well detailed 
Table 2 Typical virulence factors investigated in this study and their disease-relevance

\begin{tabular}{|c|c|c|c|c|}
\hline Toxin factor & ID in the databse & Typical pathogens and (disease) & Role of the toxin & Reference \\
\hline Aerolysin & aerA & Aeromonas spp. & Cytolytic pore-forming & {$[25]$} \\
\hline Alveolysin & alo & Bacillus anthracis & Pore-forming & {$[26]$} \\
\hline Dermonecrotic toxin & dnt & Bordetella pertussis & $\begin{array}{l}\text { Stimulating the assembly of actin } \\
\text { stress fibers and focal adhesions }\end{array}$ & {$[27,28]$} \\
\hline Pertussis toxin subunit 1 & ptxA & Bo.pertussis & $\begin{array}{l}\text { Causing disruption of host cellular } \\
\text { regulation }\end{array}$ & {$[28]$} \\
\hline Type IV secretion system protein Ptl & $\mathrm{ptICH}$ & Bo.pertussis & Secretion of pertussis toxin & {$[28]$} \\
\hline $\begin{array}{l}\text { Chlamydia protein associating with } \\
\text { death domains }\end{array}$ & CADD & $\begin{array}{l}\text { Chlamydia trachomatis (trachoma, } \\
\text { urethritis, etc.) }\end{array}$ & Inducing cell apoptosis & {$[29]$} \\
\hline Perfringolysin $\mathrm{O}$ & pfo & $\begin{array}{l}\text { Clostridium perfringens (food } \\
\text { poisoning) }\end{array}$ & Pore-forming & {$[30]$} \\
\hline Glucosyltransferase toxin B & toxB & $\begin{array}{l}\text { Cl. sordellii } \\
\text { Cl. difficile (diarrhea) }\end{array}$ & Cytopathic effects & {$[31]$} \\
\hline Zeta toxin family protein & ZETA & Coxiella sp.DG_40 & Inhibiting cell wall biosynthesis & {$[32]$} \\
\hline Shiga toxin 1 & stx1 & $\begin{array}{l}\text { Escherichia coli (diarrhea) } \\
\text { Shigella dysenteriae (Shigellosis) }\end{array}$ & Haemolytic uraemic syndrome & {$[20]$} \\
\hline Toxin CdiA & cdiA & $\begin{array}{l}\text { E. coli } \\
\text { Yersinia pestis (plaque) }\end{array}$ & $\begin{array}{l}\text { Decreasing aerobic respiration and } \\
\text { ATP levels }\end{array}$ & {$[33]$} \\
\hline Shiga-like toxin 2 & stx2 & $\begin{array}{l}\text { Enterobacteria phage } 933 \mathrm{~W} \\
\text { E. coli }\end{array}$ & Haemolytic uraemic syndrome & {$[34]$} \\
\hline Repeats-in toxin & $\operatorname{rtx} A$ & $\begin{array}{l}\text { Legionella pneumophila (Legionnar- } \\
\text { ies' disease) } \\
\text { Aeromonas dhakensis (gastroenteri- } \\
\text { tis, septicemia) }\end{array}$ & Adherence and pore forming & {$[35,36]$} \\
\hline $\begin{array}{l}\text { Cholera toxin secretion protein } \\
\text { EpsF }\end{array}$ & epsF & Le.pneumophila & Toxin secretion & {$[37]$} \\
\hline Toxin secretion ATP binding protein & LWT1SS & Le. waltersii & Toxin secretion & {$[38]$} \\
\hline $\begin{array}{l}\text { 1-phosphatidylinositol phosphodi- } \\
\text { esterase }\end{array}$ & $\mathrm{PLC}$ & Listeria monocytogenes (listeriosis) & $\begin{array}{l}\text { Lysis of the phagolysosomal } \\
\text { membrane }\end{array}$ & {$[39]$} \\
\hline Listeriolysin $\mathrm{O}$ & hly & Li. monocytogenes (listeriosis) & Pore forming, hemolysin & {$[40,41]$} \\
\hline $\begin{array}{l}\text { Outer membrane channel protein } \\
\text { CpnT }\end{array}$ & cpnT & Mycobacterium tuberculosis & Nutrient uptake & {$[42]$} \\
\hline RNA interferase & $\begin{array}{l}\text { mazF/pemK/ndoA/relE/ } \\
\text { relK/relG/yoeB/higB/ } \\
\text { mvpA }\end{array}$ & $\begin{array}{l}\text { Proteus vulgaris (wound infections) } \\
\text { My. tuberculosis (tuberculosis) } \\
\text { E. coli }\end{array}$ & $\begin{array}{l}\text { Cleavage of cellular mRNAs, inhibit- } \\
\text { ing growth }\end{array}$ & {$[43-48]$} \\
\hline Hemolytic phospholipase C & $\mathrm{plcH}$ & $\begin{array}{l}\text { Pseudomonas Aeruginosa } \\
\text { Cl. perfringens (food poisoning) }\end{array}$ & Membrane-damaging & {$[49]$} \\
\hline ADP-ribosyltransferase toxin & exos & Ps. aeruginosa & Inhibition of phagocytosis & {$[50]$} \\
\hline Ornithine carbamoyltransferase & $\operatorname{argK}$ & Ps. savastanoi & $\begin{array}{l}\text { Promoting survival and patho- } \\
\text { genicity }\end{array}$ & {$[51]$} \\
\hline Exoenzyme U & exoU & Ps. aeruginosa & Membrane-lytic and cytotoxic & {$[52]$} \\
\hline Exotoxin A & ETA & $\begin{array}{l}\text { Ps. aeruginosa (eye and wound } \\
\text { infections) }\end{array}$ & $\begin{array}{l}\text { ADP-ribosylating eukaryotic elon- } \\
\text { gation factor } 2\end{array}$ & {$[53]$} \\
\hline Mono(ADP-ribosyl)transferase & spvB & Salmonella dublin (gastroenteritis) & $\begin{array}{l}\text { ADP-ribosylating, destabilizing } \\
\text { cytoskeleton }\end{array}$ & {$[54]$} \\
\hline Adenylate cyclase & cyaA & $\begin{array}{l}\text { Sa. choleraesuis (typhoid fever) } \\
\text { Bo. pertussis (whooping cough) } \\
\text { Ba. anthracis (anthrax) }\end{array}$ & $\begin{array}{l}\text { Pore-forming with cAMP-elevating } \\
\text { activity }\end{array}$ & {$[55]$} \\
\hline Endonuclease VapC & vapC & $\begin{array}{l}\text { Shigella flexneri (diarrhea) } \\
\text { Sa. Dublin } \\
\text { My. Tuberculosis } \\
\text { Coxiella burnetii (Q fever) }\end{array}$ & tRNase activities & {$[45]$} \\
\hline Leucotoxin & luk & $\begin{array}{l}\text { Staphylococcus aureus (sinusitis, } \\
\text { skin abscess) }\end{array}$ & Lysis of leukocytes & {$[56]$} \\
\hline Exfoliative toxin & ET & St. aureus & Proteolytic activity & {$[57]$} \\
\hline
\end{tabular}


in the GenBank annotation record. Such a cross-validation positively indicated that the Local BLASTP procedure established here is useful in predicting toxin genes in unknown genomes. Yet for a semi-quantitative method to estimate toxin factors in metagenomes, a false positive analysis is required to examine to what level mismatch is included in the Local BLASTP results. Actually, the cut-off values of identity greatly impact the homolog virulence factor abundance returned. At cut-off values of $40 \%$ for identity and 20 aa for alignment length, only four records for Clostridium perfringens ATCC 13124 genome query were returned after duplication removal, one for 1-phosphatidylinositol phosphodiesterase, one for pore-forming alveolysin, one for Ornithine carbamoyltransferase and one for RNA interferase NdoA. At a cut-off identity value of $35 \%$, one more record (Toxin secretion ATP binding protein) was returned. This means that the Local BLASTP procedure was able to detect the virulence factors in unknown genomic dataset at least semi-quantitatively, with proper cut-off values for data quality control. The accuracy of the BLASTP procedure in virulence factor detection was further tested using the genomes of Bacillus thuringiensis serovar konkukian str. 97-27 (AE017355.1) and Helicobacter pylori 26695 (AE000511.1).

As mentioned above, functional genes including toxin factors may partly evolve through lateral gene transfer, which makes their taxonomic affiliation difficult. It is thus interesting to explore how specific toxin factors are associated with the taxonomic units of pathogens. Here, I explored this issue by investigating the taxonomic distribution of homologs of toxins retrieved from the GenBank database. Generally, at a lower expectation value, most toxins were associated with a specific group of pathogens. For example, at the default cut-off $E$ value, 241 out of 242 returned records of Mycobacterium tuberculosis RelE homologs fell within the phylum Actinobacteria. Moreover, $89 \%$ of these homologs were from the genus Mycobacterium, while $99.7 \%$ of Yersinia pestis CdiA homologs and $92.7 \%$ of Bordetella pertussis cya homologs belonged to Proteobacteria, and homologs of Aeromonas dhakensis repeats-in toxin (RtxA) were mostly associated with the class Gammaproteobacteria (206 out of 242). However, no obvious genus-toxin association was identified. It is worth noting that these results largely depended on the availability of toxin sequences in each taxonomic unit. The lack of a genus-toxin association basically denied the possibility of detecting a specific pathogen using a specific toxin as a single signature.

It is still not clear whether virulence secretion proteins are specific for pathogen detection as signatures, though they are essential for virulence process [20]. For example, the contact-dependent toxin delivery protein CdiA

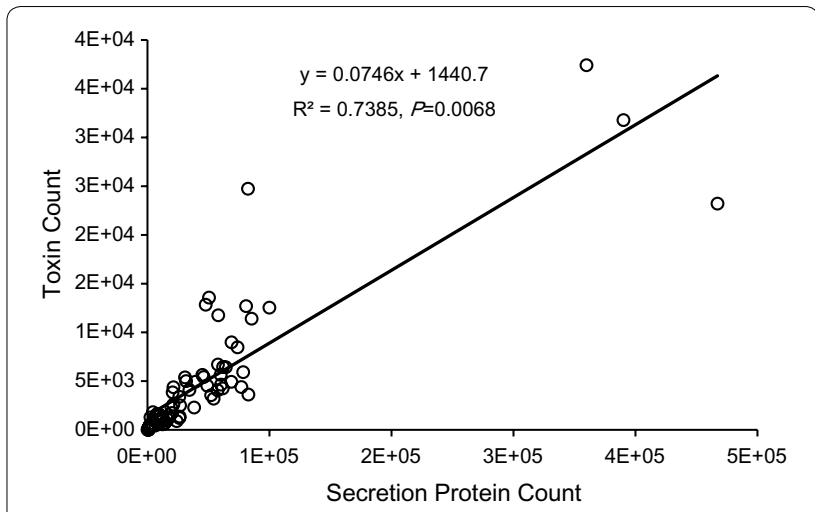

Fig. 1 Correlation between relative abundance of toxins and secretion proteins in the global microbiomes $(N=69)$

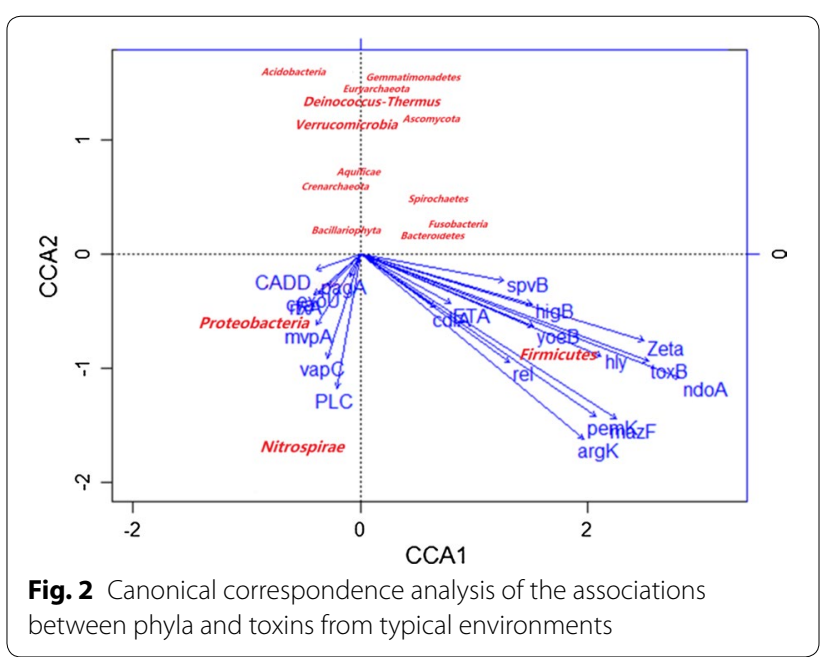

was found to be widespread in bacteria [33]. The relative abundance of secretion proteins in the 69 microbiomes was determined as well as that of the toxins which are essential to virulence processes. The results of the present study showed that the abundance of secretion proteins selected in the database was strongly correlated with the toxin abundance $\left(R^{2}=0.74, P=0.0068\right.$, Fig. 1$)$. The most abundant secretion proteins included $L$. waltersii toxin secretion protein (LWT1SS), L. pneumophila toxin secretion protein ApxIB, and Aeromonas hydrophila RTX transporter (RtxB) (data not shown). Further exploration indicated that although $A$. hydrophila RtxB homologs from GenBank were found in all Proteobacteria classes, most of the RtxB-harboring species have been reported to be pathogens, including Vibrio spp. [64, 66], Pseudomonas spp., Neisseria meningitides [67], Ralstonia spp. [68], and Yersinia spp. [21]. This may imply the pathogen-specific nature of secretion proteins included in the database, and that toxin secretion proteins can be used as signatures for pathogen detection as well. 


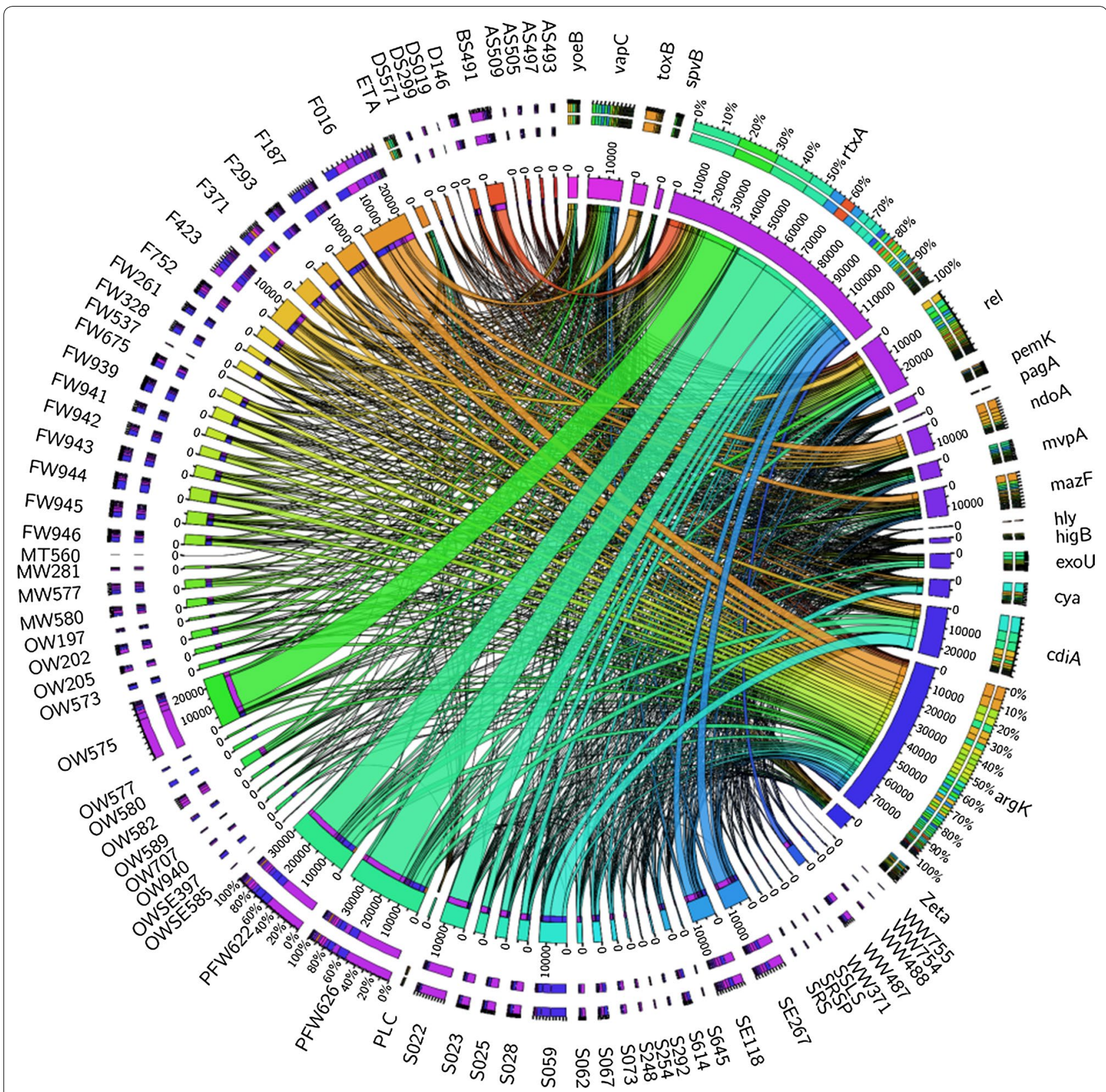

Fig. 3 Circular visualization of the toxin abundance in the microbiomes selected from locations worldwide. The designated environment abbreviation can be found in Table 1

Toxin-phyla CCA results showed that all phyla can be clearly separated into two groups, and that almost all toxins were associated with Proteobacteria, Nitrospirae, and Firmicutes (Fig. 2). Considering the phylumspecificity of the toxins stated above, these results can be biased because of the taxonomic affiliation of toxins included in the Local BLASTP database. The taxonomic distribution proportion of currently available genomes of identified pathogens was reflected in the toxin database, with Proteobacteria and Firmicutes accounting for the majority of the genomes. However, the CCA results may also indicate, at least in part, a proportional lack of pathogens in some phyla, such as Crenarchaeota, Euryarchaeota, Verrucomicrobia, and Bacteroidetes [69]. 


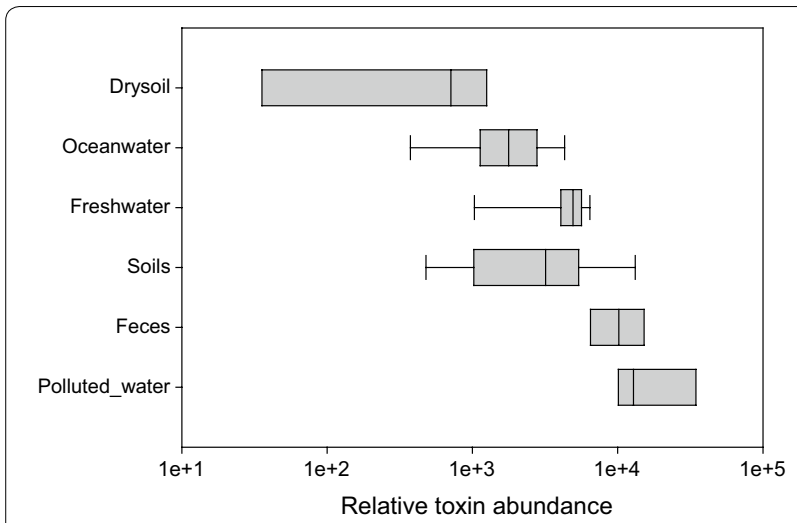

Fig. 4 A Boxplot showing the relative abundance of toxins detected from the metagenomes in this study. Drysoil includes the desert soil and desert mine tailings

Archaea cannot easily absorb phage particles because of their extracellular structures, which differ from bacteria [70]. A recent study by Li et al. [9] also found that the five most abundant bacterial pathogens were from either Proteobacteria or Firmicutes in wastewater microbiomes. Taken together, these findings could indicate that Proteobacteria or Firmicutes were evolutionarily enriched with pathogens when they dominated most environmental microbiomes on the planet [71,72].

Interestingly, there was a strong association between the phylum Nitrospirae and toxins of RNase inteferases (MvpA and MapC) and Listeria monocytogenes1phosphatidylinositol phosphodiesterase PLC. Further searches against the UniProt database [73] revealed no homologous records of MvpA and PLC from Nitrospirae, and only 109 out of 15,574 bacterial records for VapC were from Nitrospirae. These findings imply that there may be many more Nitrospirae pathogens harboring MvpA and PLC that have yet to be discovered.

The screening of toxins in the 69 global microbiomes revealed the most prevalent toxins and pathogenenriched environments. Specifically, the results showed that pore-forming RTX toxin and ornithine carbamoyltransferase ArgK were most prevalent globally in terms of both occurrence and relative abundance (Fig. 3). RTX toxins comprise a large family of pore-forming exotoxins. Known homologs in the GenBank database of Aeromonas dhakensis RtxA were mainly in the genera of Aeromonas, Pseudomonas (e.g., CP015992), Vibrio (e.g., CP002556), and Legionella (e.g., CP015953). These genera are well known to be associated with gastroenteritis, eye and wound infections, cholera and legionellosis, and RTX toxins are a key part of the virulence systems of each of these conditions [74-77]. The $\operatorname{argK}$ gene is a part of the
Pht cluster, which contains genes for the synthesis of phaseolotoxin in Ps. syringae pv. phaseolicola [78]. ArgK plays an essential role in the survival and pathogenicity of Ps. syringae. Known ArgK proteins mainly come from Pseudomonas, Escherichia, and Mycobacterium, which are widespread and persistent in the environment [79]. In addition, Cya is worth noting as an essential unit of Bacillus anthracis virulence that causes anthrax and may lead to mammalian death [80]. Known homologs in the GenBank database of Bacillus anthracis Cya were mainly from Bacillus spp., Bordetella spp., Pseudomonas aeruginosa, Yersinia pseudotuberculosis, and Vibrio spp. Their presence in the environment should be carefully examined and precautions should be taken to prevent infection by these organisms since many of them are associated with very common diseases such as whooping cough.

The main purpose of the Local BLASTP method established here was to screen pathogen-enriched environments to enable development of precautionary measures. Our results clearly indicated that contaminated freshwater, feces, and harbor sediment microbiomes were rich in pathogens (Fig. 4). Although there was no detailed background information regarding these environments in this study, the results presented herein may provide important implications for pathogen-related risk control. Surprisingly, two lake water microbiomes from Nanjing, China contained the highest toxin factors among the 69 samples. Further investigation of the location and contamination status supported the sewage-nature of the lake water. In China, most polluted lakes receive sewage that includes feces materials [81]. According to an official survey conducted in 2015, Nanjing has 28 lakes with a total area of $14 \mathrm{~km}^{2}$, among which $96.4 \%$ are classified as polluted (Class V of the national standard). Studies have documented that pathogens tend to be enriched in polluted waters [13]. It is not surprising to find that feces samples had very high abundance of toxins. Epidemical statistics have indicated that feces are the most important pathway for diarrheal diseases, which is a leading cause of childhood death globally [82]. Meanwhile, dry soil environments like desert soil and desert tailings were found to contain relatively less toxin factors. It is still unclear to what extent the environments stressed by long-lasting drought or metal pollution suppress the colonization and development of pathogens [83]. In all, the association between environmental factors and pathogen abundance merits a systematic exploration in the future.

\section{Conclusions}

A Local BLASTP procedure was established for rapid detection of toxins in environmental samples. Screening of global microbiomes in this study provided a 
quantitative estimate of the most prevalent toxins and most pathogen-enriched environments.

\section{Additional file}

Additional file 1. A toxin factor database for metagenomic detection of environmental pathogens through Local BLASTP.

\section{Abbreviations}

BLAST: basic local alignment search tool; PCR: polymerase chain reaction.

\section{Acknowledgements}

I thank Dr. Philip L. Bond and The University of Queensland for providing training in bioinformatics. I would like to thank LetPub (http://www.letpub.com) for providing linguistic assistance during the preparation of this manuscript. I also thank the founders of the existing pathogen-relevant database, particularly the Virulence Factor Database, which provided valuable reference for the build-up of the toxin database in this study.

\section{Authors' contributions}

$\mathrm{XL}$ initiated the study, analyzed the data, and wrote the manuscript. The author read and approved the final manuscript.

\section{Funding}

This work was financially supported by the National Key Research and Development Program of China (2018YFD0800306), the National Natural Science Foundation of China (41877414), and Hebei Science Fund for Distinguished Young Scholars (D2018503005).

\section{Availability of data and materials}

The toxin database is available in the Additional file 1: Materials. All toxin abundance data in this study can be provided by the author upon request.

\section{Ethics approval and consent to participate}

Not applicable.

\section{Consent for publication}

Not applicable.

\section{Competing interests}

The authors declare that they have no competing interests.

Received: 22 February 2019 Accepted: 22 May 2019

Published online: 11 June 2019

\section{References}

1. Baumgardner DJ (2012) Soil-related bacterial and fungal infections. J Am Board Fam Med 25(5):734-744. https://doi.org/10.3122/jabfm 2012.05.110226

2. Jeffery S, van der Putten WH (2011) Soil borne diseases of Humans. Joint Research Centre, Institute for Environment and Sustainability Ispra, Italy

3. Whiley H, Bentham R (2011) Legionella longbeachae and Legionellosis. Emerg Infect Dis 17(4):579-583. https://doi.org/10.3201/eid1704.100446

4. Cooper RC, Golueke CG (1979) Survival of enteric bacteria and viruses in compost and its leachate. Compost Sci Land Ut 20(2):29-35

5. Dan TBB, Wynne D, Manor Y (1997) Survival of enteric bacteria and viruses in Lake Kinneret, Israel. Water Res 31(11):2755-2760

6. Keswick BH, Gerba CP, Secor SL, Cech I (1982) Survival of enteric viruses and indicator bacteria in groundwater. J Environ Sci Health $A$ 17(6):903-912

7. Wait DA, Sobsey MD (2001) Comparative survival of enteric viruses and bacteria in Atlantic Ocean seawater. Water Sci Technol 43(12):139-142
8. Miller RR, Montoya V, Gardy JL, Patrick DM, Tang P (2013) Metagenomics for pathogen detection in public health. Genome Med 5:81. https://doi. org/10.1186/gm485

9. Li B, Ju F, Cai L, Zhang T (2015) Profile and fate of bacterial pathogens in sewage treatment plants revealed by high-throughput metagenomic approach. Environ Sci Technol 49(17):10492-10502. https://doi. org/10.1021/acs.est.5b02345

10. Amha YM, Anwar MZ, Kumaraswamy R, Henschel A, Ahmad F (2017) Mycobacteria in municipal wastewater treatment and reuse: microbial diversity for screening the occurrence of clinically and environmentally relevant species in arid regions. Environ Sci Technol 51(5):3048-3056. https://doi.org/10.1021/acs.est.6b05580

11. Granberg F, Vicente-Rubiano M, Rubio-Guerri C, Karlsson OE, Kukielka D, Belak S, Sanchez-Vizcaino JM (2013) Metagenomic detection of viral pathogens in Spanish honeybees: co-infection by aphid lethal paralysis, Israel acute paralysis and Lake Sinai viruses. PLoS ONE 8(2):e57459. https ://doi.org/10.1371/journal.pone.0057459

12. Yang J, Yang F, Ren LL, Xiong ZH, Wu ZQ, Dong J, Sun LL, Zhang T, Hu YF, Du J, Wang JW, Jin Q (2011) Unbiased parallel detection of viral pathogens in clinical samples by use of a metagenomic approach. J Clin Microbiol 49(10):3463-3469. https://doi.org/10.1128/Jcm.00273-11

13. Bibby K (2013) Metagenomic identification of viral pathogens. Trends Biotechnol 31(5):11-15. https://doi.org/10.1016/j.tibtech.2013.01.016

14. Nakamura S, Yang CS, Sakon N, Ueda M, Tougan T, Yamashita A, Goto N, Takahashi K, Yasunaga T, Ikuta K, Mizutani T, Okamoto Y, Tagami M, Morita R, Maeda N, Kawai J, Hayashizaki Y, Nagai Y, Horii T, lida T, Nakaya T (2009) Direct metagenomic detection of viral pathogens in nasal and fecal specimens using an unbiased high-throughput sequencing approach. PLoS ONE 4(1):e4219. https://doi.org/10.1371/journal.pone.0004219

15. Fukui Y, Aoki K, Okuma S, Sato T, Ishii Y, Tateda K (2015) Metagenomic analysis for detecting pathogens in culture-negative infective endocarditis. J Infect Chemother 21(12):882-884. https://doi.org/10.1016/j. jiac.2015.08.007

16. Baldwin DA, Feldman M, Alwine JC, Robertson ES (2014) Metagenomic assay for identification of microbial pathogens in tumor tissues. Mbio 5(5):e01714-14. https://doi.org/10.1128/mbio.01714-14

17. Achtman M, Wagner M (2008) Microbial diversity and the genetic nature of microbial species. Nat Rev Microbiol 6(6):431-440

18. Liao PY, Lee KH (2010) From SNPs to functional polymorphism: the insight into biotechnology applications. Biochem Eng J 49(2):149-158. https:// doi.org/10.1016/j.bej.2009.12.021

19. Sokurenko EV, Hasty DL, Dykhuizen DE (1999) Pathoadaptive mutations: gene loss and variation in bacterial pathogens. Trends Microbiol 7(5):191-195. https://doi.org/10.1016/S0966-842x(99)01493-6

20. Strauch E, Lurz R, Beutin L (2001) Characterization of a Shiga toxinencoding temperate bacteriophage of Shigella sonnei. Infect Immun 69(12):7588-7595. https://doi.org/10.1128/lai.69.12.7588-7595.2001

21. Chen LH, Zheng DD, Liu B, Yang J, Jin Q (2016) VFDB 2016: hierarchical and refined dataset for big data analysis-10 years on. Nucleic Acids Res 44(D1):D694-D697. https://doi.org/10.1093/nar/gkv1239

22. Water Environment Federation (2009) Manure pathogens: manure management, regulations, and water quality protection. WEF Press, Water Environment Federation, Alexandria

23. Bateman A, Martin MJ, O'Donovan C, Magrane M, Alpi E, Antunes R, Bely B, Bingley M, Bonilla C, Britto R, Bursteinas B, Bye-A-Jee H, Cowley A, Da Silva A, De Giorgi M, Dogan T, Fazzini F, Castro LG, Figueira L, Garmiri P, Georghiou G, Gonzalez D, Hatton-Ellis E, Li WZ, Liu WD, Lopez R, Luo J, Lussi Y, MacDougall A, Nightingale A, Palka B, Pichler K, Poggioli D, Pundir S, Pureza L, Qi GY, Rosanoff S, Saidi R, Sawford T, Shypitsyna A, Speretta E, Turner E, Tyagi N, Volynkin V, Wardell T, Warner K, Watkins X, Zaru R, Zellner H, Xenarios I, Bougueleret L, Bridge A, Poux S, Redaschi N, Aimo L, Argoud-Puy G, Auchincloss A, Axelsen K, Bansal P, Baratin D, Blatter MC, Boeckmann B, Bolleman J, Boutet E, Breuza L, Casal-Casas C, de Castro E, Coudert E, Cuche B, Doche M, Dornevil D, Duvaud S, Estreicher A, Famiglietti L, Feuermann M, Gasteiger E, Gehant S, Gerritsen V, Gos A, Gruaz-Gumowski N, Hinz U, Hulo C, Jungo F, Keller G, Lara V, Lemercier P, Lieberherr D, Lombardot T, Martin X, Masson P, Morgat A, Neto T, Nouspikel N, Paesano S, Pedruzzi I, Pilbout S, Pozzato M, Pruess M, Rivoire C, Roechert B, Schneider M, Sigrist C, Sonesson K, Staehli S, Stutz A, Sundaram S, Tognolli M, Verbregue L, Veuthey AL, Wu CH, Arighi CN, Arminski L, Chen CM, Chen YX, Garavelli JS, Huang HZ, Laiho K, McGarvey P, Natale 
DA, Ross K, Vinayaka CR, Wang QH, Wang YQ, Yeh LS, Zhang J, Consortium U (2017) UniProt: the universal protein knowledgebase. Nucleic Acids Res 45(D1):D158-D169. https://doi.org/10.1093/nar/gkw1099

24. Hoffmann R (2008) A wiki for the life sciences where authorship matters. Nat Genet 40(9):1047-1051. https://doi.org/10.1038/ng.f.217

25. Howard SP, Garland WJ, Green MJ, Buckley JT (1987) Nucleotide sequence of the gene for the hole-forming toxin aerolysin of Aeromonas hydrophila. J Bacteriol 169(6):2869-2871

26. Geoffroy C, Mengaud J, Alouf JE, Cossart P (1990) Alveolysin, the thiol-activated toxin of Bacillus alvei, is homologous to listeriolysin $\mathrm{O}$, perfringolysin $\mathrm{O}$, pneumolysin, and streptolysin $\mathrm{O}$ and contains a single cysteine. J Bacteriol 172(12):7301-7305. https://doi.org/10.1128/ jb.172.12.7301-7305.1990

27. Matsuzawa T, Kashimoto T, Katahira J, Horiguchi Y (2002) Identification of a receptor-binding domain of bordetella dermonecrotic toxin. Infect Immun 70(7):3427-3432. https://doi.org/10.1128/iai.70.7.3427-3432.2002

28. Weiss AA, Johnson FD, Burns DL (1993) Molecular characterization of an operon required for pertussis toxin secretion. Proc Natl Acad Sci U S A 90(7):2970-2974. https://doi.org/10.1073/pnas.90.7.2970

29. Schwarzenbacher $R$, Stenner-Liewen F, Liewen $H$, Robinson $H$, Yuan $H$, Bossy-Wetzel E, Reed JC, Liddington RC (2004) Structure of the chlamydia protein CADD reveals a redox enzyme that modulates host cell apoptosis. J Biol Chem 279(28):29320-29324. https://doi.org/10.1074/jbc.M4012 68200

30. Rossjohn J, Polekhina G, Feil SC, Morton CJ, Tweten RK, Parker MW (2007) Structures of perfringolysin O suggest a pathway for activation of cholesterol-dependent cytolysins. J Mol Biol 367(5):1227-1236. https:// doi.org/10.1016/j.jmb.2007.01.042

31. Lyras D, O'Connor JR, Howarth PM, Sambol SP, Carter GP, Phumoonna T, Poon R, Adams V, Vedantam G, Johnson S, Gerding DN, Rood JI (2009) Toxin B is essential for virulence of Clostridium difficile. Nature 458(7242):1176-1181. https://doi.org/10.1038/nature07822

32. Lioy VS, Machon C, Tabone M, Gonzalez-Pastor JE, Daugelavicius R, Ayora $\mathrm{S}$, Alonso JC (2012) The $\zeta$ toxin induces a set of protective responses and dormancy. PLoS ONE 7(1):e30282. https://doi.org/10.1371/journ al.pone.0030282

33. Aoki SK, Diner EJ, de Roodenbeke CT, Burgess BR, Poole SJ, Braaten BA, Jones AM, Webb JS, Hayes CS, Cotter PA, Low DA (2010) A widespread family of polymorphic contact-dependent toxin delivery systems in bacteria. Nature 468(7322):439-442. https://doi.org/10.1038/nature09490

34. Schmidt H, Scheef J, JanetzkiMittmann C, Datz M, Karch H (1997) An ileX tRNA gene is located close to the Shiga toxin II operon in enterohemorrhagic Escherichia coli O157 and non-O157 strains. FEMS Microbiol Lett 149(1):39-44. https://doi.org/10.1016/S0378-1097(97)00051-7

35. D'Auria G, Jimenez N, Peris-Bondia F, Pelaz C, Latorre A, Moya A (2008) Virulence factor rtx in Legionella pneumophila, evidence suggesting it is a modular multifunctional protein. BMC Genomics 9:1. https://doi. org/10.1186/1471-2164-9-14

36. Rasmussen-Ivey CR, Figueras MJ, McGarey D, Liles MR (2016) Virulence factors of Aeromonas hydrophila: in the wake of reclassification. Front Microbiol 7:1337. https://doi.org/10.3389/fmicb.2016.01337

37. Sandkvist M, Michel LO, Hough LP, Morales VM, Bagdasarian M, Koomey M, DiRita VJ, Bagdasarian M (1997) General secretion pathway (eps) genes required for toxin secretion and outer membrane biogenesis in Vibrio cholerae. J Bacteriol 179(22):6994-7003. https://doi.org/10.1128/ jb.179.22.6994-7003.1997

38. Söderberg MA, Rossier O, Cianciotto NP (2004) The type II protein secretion system of Legionella pneumophila promotes growth at low temperatures. J Bacteriol 186(12):3712-3720. https://doi.org/10.1128/ jb.186.12.3712-3720.2004

39. Henner DJ, Yang M, Chen E, Hellmiss R, Rodriguez H, Low MG (1988) Sequence of the Bacillus thuringiensis phosphatidylinositol specific phospholipase-c. Nucleic Acids Res 16(21):10383. https://doi.org/10.1093/ nar/16.21.10383

40. Cossart P (1988) The listeriolysin O-gene-a chromosomal locus crucial for the virulence of listeria-monocytogenes. Infection 16:S157-S159. https://doi.org/10.1007/Bf01639740

41. Hamon MA, Batsche E, Regnault B, Tham TN, Seveau S, Muchardt C, Cossart P (2007) Histone modifications induced by a family of bacterial toxins. Proc Natl Acad Sci U S A 104(33):13467-13472. https://doi. org/10.1073/pnas.0702729104
42. Danilchanka O, Pires D, Anes E, Niederweis M (2015) The Mycobacterium tuberculosis outer membrane channel protein CpnT confers susceptibility to toxic molecules. Antimicrob Agents chemother 59(4):2328-2336. https ://doi.org/10.1128/Aac.04222-14

43. Hurley JM, Woychik NA (2009) Bacterial toxin HigB associates with ribosomes and mediates translation-dependent mRNA cleavage at A-rich sites. J Biol Chem 284(28):18605-18613. https://doi.org/10.1074/jbc. M109.008763

44. Korch SB, Contreras H, Clark-Curtiss JE (2009) Three Mycobacterium tuberculosis rel toxin-antitoxin modules inhibit mycobacterial growth and are expressed in infected human macrophages. J Bacteriol 191(5):1618-1630. https://doi.org/10.1128/jb.01318-08

45. Pullinger GD, Lax AJ (1992) A salmonella-dublin virulence plasmid locus that affects bacterial-growth under nutrient-limited conditions. Mol Microbiol 6(12):1631-1643. https://doi.org/10.1111/j.1365-2958.1992. tb00888.x

46. Tian QB, Ohnishi M, Tabuchi A, Terawaki Y (1996) A new plasmid-encoded proteic killer gene system: cloning, sequencing, and analysing hig locus of plasmid Rts1. Biochem Biophys Res Commun 220(2):280-284. https:// doi.org/10.1006/bbrc.1996.0396

47. Pellegrini O, Mathy N, Gogos A, Shapiro L, Condon C (2005) The Bacillus subtilis ydcDE operon encodes an endoribonuclease of the MazF/PemK family and its inhibitor. Mol Microbiol 56(5):1139-1148. https://doi.org/10 $.1111 / j .1365-2958.2005 .04606 . x$

48. Yamaguchi Y, Inouye M (2011) Regulation of growth and death in Escherichia coli by toxin-antitoxin systems. Nat Rev Microbiol 9(11):779-790. https://doi.org/10.1038/nrmicro2651

49. Songer JG (1997) Bacterial phospholipases and their role in virulence. Trends Microbiol 5(4):156-161. https://doi.org/10.1016/s0966 $-842 \times(97) 01005-6$

50. Krueger KM, Barbieri JT (1995) The family of bacterial ADP-ribosylating exotoxins. Clin Microbiol Rev 8(1):34-47

51. Hatziloukas E, Panopoulos NJ (1992) Origin, structure, and regulation of argK, encoding the phaseolotoxin-resistant ornithine carbamoyltransferase in Pseudomonas syringae pv. phaseolicola, and functional expression of argK in transgenic tobacco. J Bacteriol 174(18):5895-5909. https:// doi.org/10.1128/jb.174.18.5895-5909.1992

52. Phillips RM, Six DA, Dennis EA, Ghosh P (2003) In vivo phospholipase activity of the Pseudomonas aeruginosa cytotoxin ExoU and protection of mammalian cells with phospholipase A2 inhibitors. J Biol Chem 278(42):41326-41332. https://doi.org/10.1074/jbc.M302472200

53. Yates SP, Merrill AR (2004) Elucidation of eukaryotic elongation factor-2 contact sites within the catalytic domain of Pseudomonas aeruginosa exotoxin A. Biochem J 379:563-572. https://doi.org/10.1042/Bj20031731

54. Lesnick ML, Reiner NE, Fierer J, Guiney DG (2001) The Salmonella spvB virulence gene encodes an enzyme that ADP-ribosylates actin and destabilizes the cytoskeleton of eukaryotic cells. Mol Microbiol 39(6):14641470. https://doi.org/10.1046/j.1365-2958.2001.02360.x

55. Skopova K, Tomalova B, Kanchev I, Rossmann P, Svedova M, Adkins I, Bibova I, Tomala J, Masin J, Guiso N, Osicka R, Sedlacek R, Kovar M, Sebo P (2017) cAMP-elevating capacity of the adenylate cyclase toxin-hemolysin is sufficient for lung infection but not for full virulence of Bordetella pertussis. Infect Immun 85(6):e00937-16. https://doi.org/10.1128/iai.00937 $-16$

56. Labandeira-Rey M, Couzon F, Boisset S, Brown EL, Bes M, Benito Y, Barbu EM, Vazquez V, Hook M, Etienne J, Vandenesch F, Bowden MG (2007) Staphylococcus aureus Panton-Valentine leukocidin causes necrotizing pneumonia. Science 315(5815):1130-1133. https://doi.org/10.1126/scien ce.1137165

57. Bukowski M, Wladyka B, Dubin G (2010) Exfoliative toxins of Staphylococcus aureus. Toxins 2(5):1148-1165. https://doi.org/10.3390/toxins2051148

58. Li X, Zhu YG, Shaban B, Bruxner TJ, Bond PL, Huang L (2015) Assessing the genetic diversity of Cu resistance in mine tailings through highthroughput recovery of full-length copA genes. Sci Rep 5:13258. https:// doi.org/10.1038/srep13258

59. Li XF, Bond PL, Huang LB (2017) Diversity of As metabolism functional genes in Pb-Zn mine tailings. Pedosphere 27(3):630-637. https://doi. org/10.1016/S1002-0160(17)60357-6

60. Larkin MA, Blackshields G, Brown NP, Chenna R, McGettigan PA, McWilliam H, Valentin F, Wallace IM, Wilm A, Lopez R, Thompson JD, Gibson 
TJ, Higgins DG (2007) Clustal W and clustal X version 2.0. Bioinformatics 23(21):2947-2948

61. Kumar S, Stecher G, Tamura K (2016) MEGA7: Molecular evolutionary genetics analysis version 7.0 for bigger datasets. Mol Biol Evol 33(7):18701874. https://doi.org/10.1093/molbev/msw054

62. Krzywinski M, Schein J, Birol I, Connors J, Gascoyne R, Horsman D, Jones SJ, Marra MA (2009) Circos: an information aesthetic for comparative genomics. Genome Res 19(9):1639-1645. https://doi.org/10.1101/ gr.092759.109

63. R: A language and environment for statistical computing (2016) R Foundation for Statistical Computing

64. Oksanen J, Blanchet FG, Friendly M, Kindt R, Legendre P, McGlinn D, Minchin PR, O'Hara RB, Simpson GL, Solymos P, Henry M, Stevens H, Szoecs E, Wagner H (2017) vegan: Community ecology package. https:// cran.r-project.org/web/packages/vegan/index.html

65. Gupta SK, Padmanabhan BR, Diene SM, Lopez-Rojas R, Kempf M, Landraud L, Rolain JM (2014) ARG-ANNOT, a new bioinformatic tool to discover antibiotic resistance genes in bacterial genomes. Antimicrob Agents Chemother 58(1):212-220

66. Austin B, Zhang XH (2006) Vibrio harveyi: a significant pathogen of marine vertebrates and invertebrates. Lett Appl Microbiol 43(2):119-124. https:// doi.org/10.1111/j.1472-765X.2006.01989.x

67. Rouphael NG, Stephens DS (2012) Neisseria meningitidis: biology, microbiology, and epidemiology. Methods Mol Biol 799:1-20. https://doi. org/10.1007/978-1-61779-346-2_1

68. Xu J, Zheng HJ, Liu L, Pan ZC, Prior P, Tang B, Xu JS, Zhang H, Tian Q, Zhang LQ, Feng J (2011) Complete genome sequence of the plant pathogen Ralstonia solanacearum strain Po82. J Bacteriol 193(16):4261-4262. https://doi.org/10.1128/Jb.05384-11

69. Ecker DJ, Sampath R, Willett P, Wyatt JR, Samant V, Massire C, Hall TA, Hari K, McNeil JA, Buchen-Osmond C, Budowle B (2005) The microbial rosetta stone database: a compilation of global and emerging infectious microorganisms and bioterrorist threat agents. BMC Microbiol 5:19. https://doi. org/10.1186/1471-2180-5-19

70. Gill EE, Brinkman FSL (2011) The proportional lack of archaeal pathogens: do viruses/phages hold the key? BioEssays 33(4):248-254. https://doi. org/10.1002/bies.201000091

71. Fierer N, Bradford MA, Jackson RB (2007) Toward an ecological classification of soil bacteria. Ecology 88(6):1354-1364. https://doi. org/10.1890/05-1839

72. Roesch LF, Fulthorpe RR, Riva A, Casella G, Hadwin AKM, Kent AD, Daroub SH, Camargo FAO, Farmerie WG, Triplett EW (2007) Pyrosequencing enumerates and contrasts soil microbial diversity. ISME J 1(4):283-290. https ://doi.org/10.1038/ismej.2007.53

73. Apweiler R, Bairoch A, Wu CH, Barker WC, Boeckmann B, Ferro S, Gasteiger E, Huang HZ, Lopez R, Magrane M, Martin MJ, Natale DA, O'Donovan C,
Redaschi N, Yeh LSL (2004) UniProt: the universal protein knowledgebase. Nucleic Acids Res 32:D115-D1 19. https://doi.org/10.1093/nar/gkh131

74. Cirillo SLG, Bermudez LE, El-Etr SH, Duhamel GE, Cirillo JD (2001) Legionella pneumophila entry gene rtXA is involved in virulence. Infect Immun 69(1):508-517. https://doi.org/10.1128/lai.69.1.508-517.2001

75. Lin W, Fullner KJ, Clayton R, Sexton JA, Rogers MB, Calia KE, Calderwood SB, Fraser C, Mekalanos JJ (1999) Identification of a Vibrio cholerae RTX toxin gene cluster that is tightly linked to the cholera toxin prophage. Proc Natl Acad Sci U S A 96(3):1071-1076. https://doi.org/10.1073/ pnas.96.3.1071

76. Suarez G, Khajanchi BK, Sierra JC, Erova TE, Sha J, Chopra AK (2012) Actin cross-linking domain of Aeromonas hydrophila repeat in toxin A (RtxA) induces host cell rounding and apoptosis. Gene 506(2):369-376. https:// doi.org/10.1016/j.gene.2012.07.012

77. Terada LS, Johansen KA, Nowbar S, Vasil Al, Vasil ML (1999) Pseudomonas aeruginosa hemolytic phospholipase $C$ suppresses neutrophil respiratory burst activity. Infect Immun 67(5):2371-2376

78. Aguilera S, De la Torre-Zavala S, Hernández-Flores JL, Murillo J, Bravo J, Alvarez-Morales A (2012) Expression of the gene for resistance to phaseolotoxin (argK) depends on the activity of genes phtABC in Pseudomonas syringae pv. phaseolicola. PLoS ONE 7(10):e46815-e46815. https://doi. org/10.1371/journal.pone.0046815

79. Velayati AA, Farnia P, Mirsaeidi M (2015) Persistence of Mycobacterium tuberculosis in environmental samples. Int J Mycobacteriol 4:1. https://doi. org/10.1016/j.jimyco.2014.11.005

80. Leppla SH (1982) Anthrax toxin edema factor-a bacterial adenylatecyclase that increases cyclic-amp concentrations in eukaryotic cells. Proc Natl Acad Sci Biol 79(10):3162-3166. https://doi.org/10.1073/ pnas.79.10.3162

81. Qiu Z (2015) Current pollution status of China's lakes. Paper presented at the The 5 th Forum for China Lakes, Jilin

82. Liu L, Johnson HL, Cousens S, Perin J, Scott S, Lawn JE, Rudan I, Campbell H, Cibulskis R, Li MY, Mathers C, Black RE, Who Unicef (2012) Global, regional, and national causes of child mortality: an updated systematic analysis for 2010 with time trends since 2000. Lancet 379(9832):21512161. https://doi.org/10.1016/S0140-6736(12)60560-1

83. Li X (2019) Technical solutions for the safe utilization of heavy metal-contaminated farmland in China: a critical review. Land Degrad Dev. https:// doi.org/10.1002/ldr.3309

\section{Publisher's Note}

Springer Nature remains neutral with regard to jurisdictional claims in published maps and institutional affiliations.

\section{Submit your manuscript to a SpringerOpen ${ }^{\odot}$ journal and benefit from:}

- Convenient online submission

- Rigorous peer review

- Open access: articles freely available online

- High visibility within the field

- Retaining the copyright to your article

Submit your next manuscript at $\boldsymbol{\nabla}$ springeropen.com 